Proceedings

\title{
Diving Lice: The Exception to the Rule That There Are No Insects in the (Deep) Ocean ${ }^{+}$
}

\author{
María Soledad Leonardi ${ }^{1}$, José E. Crespo ${ }^{2}$, Florencia A. Soto ${ }^{1}$ and Claudio R. Lazzari ${ }^{3, *}$ \\ 1 IBIOMAR-CONICET, Puerto Madryn, Argentina; leonardi@cenpat-conicet.gob.ar; fsoto@cenpat- \\ conicet.gob.ar \\ 2 CONICET- Universidad de Buenos Aires, Instituto de Ecologia', Genética y Evolución (IEGEBA), Buenos \\ Aires, Argentina; crespo@ege.fcen.uba.ar \\ ${ }^{3}$ Institut de Recherche sur la Biologie de l'Insecte, UMR CNRS 7261 - University of Tours, France; \\ claudio.lazzari@univ-tours.fr \\ * Correspondence: claudio.lazzari@univ-tours.fr \\ + Presented at the 1st International Electronic Conference on Entomology (IECE 2021), 1-15 July 2021; \\ Available online: https://iece.sciforum.net/.
}

Citation: Leonardi, M.S.; Crespo, J.E.; Soto, F.A.; Lazzari, C.R. Diving Lice: The Exception to the Rule That There Are No Insects in the (Deep) Ocean, in Proceedings of the 1st International Electronic Conference on Entomology, 1-15 July 2021, MDPI: Basel, Switzerland, doi:10.3390/IECE-10543

Published: 1 July 2021

Publisher's Note: MDPI stays neutral with regard to jurisdictional claims in published maps and institutional affiliations.

Copyright: () 2021 by the authors. Submitted for possible open access publication under the terms and conditions of the Creative Commons Attribution (CC BY) license (http://creativecommons.org/licenses/by/4.0/).

\begin{abstract}
Insects are present in virtually all possible habitats on the mainland but virtually absent in the ocean which constitutes $90 \%$ of the biosphere. Only a few species are present in the sea, but remaining at the surface, salt marshes, estuaries, or shallow waters. Remarkably, a group of species manages to endure long immersion periods in the open sea, as well as deep dives, i.e. seal lice. We discuss here some of the adaptations that allow seal lice to cope with the amphibious habits of their hosts and how they can help understanding why are insect so rare in the ocean.
\end{abstract}

Keywords: Adaptation to extreme environments; Anoplura; Echinophthiriidae; marine insects

\section{Insects and the sea}

Insects are the most ecologically and evolutionary successful organisms on Earth in terms of biomass and biodiversity [1]. They have virtually conquered any possible environment on our planet with a notable exception: the oceans [2]. Usually, in the literature, only a few species of Halobates (Heteroptera: Gerridae) are mentioned as truly marine insects living in open ocean [3]. However, these sea-skaters remain on the water surface and, therefore, are not actually exposed to high salinity, low temperature, the absence of atmospheric oxygen, and high hydrostatic pressure underwater. This absence of insects in the ocean (i.e., $90 \%$ of the biosphere) and their infrequent presence in marine habitats contrast with their profuse occurrence on the mainland, giving origin to varied scientific hypotheses and speculation [4]. In this sense, Maddrell [5] argued that the absence of insects can be explained because they would be poor competitors against crustaceans since they could not survive beyond the first few meters of the water column because their tracheal system would not be able to support the increase in the hydrostatic pressure [5]. Yet, there exists a particular group of insects that manages to survive underwater at great depths and during extended immersion periods, e.g. seal lice.

\section{The lice of the pinnipeds, living an amphibious life}

Lice (Order Phthiraptera) are the only insects that have become obligate and permanent parasites throughout their entire life, living as ectoparasites in the feathers, fur, or hairs of their hosts [6,7]. Sucking lice (suborder Anoplura) are a group of hematophagous insects from mammals, being present in all the mammalian genus, except the Monotremata, Cetacea, Sirenia, Pholidota, Edentata, and Proboscidea. Among the great diversity of Anopluran lice, the family Echinophthiriidae is unique in that they infest 
amphibious hosts, such as pinnipeds (walruses, seals, and sea lions) and the Northern river otter $[8,9]$.

Pinnipeds are diving mammals, and most sea lions and fur seals usually dive to feed [10]. The most extraordinary diver is the southern elephant seal which can reach $2000 \mathrm{~m}$ deep [11]. During the periods of feeding, pinnipeds can spend several months of the year on the open sea [12]. Therefore, during the evolutionary time, echinophthiriids managed to adapt to the amphibian biology of their hosts [13]. The survival of an originally terrestrial louse in the deep of the ocean implies necessarily that this insect managed to tolerate the particular conditions of this environment, as the high hydrostatic pressure, the low temperature, and the high salt concentration.

The adaptation of echinophthiriids to live in association with diving hosts started to be investigated only recently. This mini-review provides a reflexive glance on the state of knowledge about the adaptations of echinophthiriids, along with biological hypotheses and research ways deserving to be explored.

\section{Tolerance to immersion}

Undoubtedly, one of the greatest limitations for echinophthiriids is the fact that eggs do not survive underwater [14, 15]. Accordingly, lice reproduction could only occur during the periods that the hosts remain on land enough time to guarantee egg development, i.e. during host reproduction or molting seasons. For the life history of echinophthiriids, this implies that the number of lice generations per year should be constrained by the haul-out behavior of their hosts. For instance, for Antarctophthirus microchir from South American sea lions, the reproductive season is the only moment of the life cycle when the host spends enough time ashore and only newborn pups remain outside the water Figure $1[15,16]$. While for $A$. lobodontis from the crabeater seal, the reproduction and transmission would be only possible on juveniles [17]. Therefore, the phenology of seal lice is adapted to the biology and ecology of their hosts [18].

To evaluate the tolerance of the nymphal and imaginal stages, we performed a series of experiments depicted in Figure 1, i.e testing lice survival under different protocols of submersion and temperature [15]. We found that the first nymphs (N1) are unable to survive submerged but the following instars and adults tolerate it for several days [15]. Previous contributions by Murray and Nicholls [21], reported the death of eggs, but the survival of advanced nymphs and adults; however, N1 were not included in the experiment. Our results demonstrated that N1 survived submersion only for a couple of days. The reduced tolerance to immersions of $\mathrm{N} 1$ as compared to more advanced instars has been also alleged by Aznar et al. [15], based on the reduction of N1 in the South American sea lion pups population when they started to swim. Murray and co-workers arrived at a similar conclusion [14, 21], as well as by Kim [22] from the absence of N1 in old pups and adult pinnipeds on northern fur seals. The incapacity of N1 to survive underwater was suggested to be associated with the absence of abdominal scales [16, 22, 23], which are present over the body of the other instars.

The presence of specialized and modified spines, known as scales, is a diagnostic feature of echinophthiriids [24]. Scales are absent in the first nymphal stage [22, 23] and increase in density and size during their development $[20,23,25,26]$. Several authors have suggested that scales are related to underwater survival $[16,18,22]$. The specific role of scales has been discussed by some authors, suggesting that scales could have two main functions. Whereas Murray [20] postulated that scales protect the cuticle from mechanical damage and against desiccation, Hinton [27] proposed that scales could potentially act as a plastron retaining air and allowing respiration underwater. Unfortunately, no critical observational or experimental evidence has been yet obtained, supporting or opposing either hypothesis.

When seal lice became in contact with seawater, they confront a decrease in oxygen concentration and temperature and an increase in the hydrostatic pressure. We observed that as soon as Antarctophthirus microchir makes contact with the seawater adopted a state 
of quiescence, while for Lepidophthirus macrorhini this takes several minutes Video S1 [15, 19]. It seems that the tolerance to immersion depends on a reflex reduction in metabolism and activity triggered by contact with seawater. This behavior could decrease the need for nutrients and oxygen, allowing survival for several days underwater. However, their differential survival when submerged in normoxic or in hypoxic water strongly suggests that echinophthiriids would be able to exchange gases with the surrounding water [15], a capacity never observed previously in the group. Further anatomical and physiological research should shed light on the adaptations and mechanisms of aquatic respiration.

\section{Tolerance to hydrostatic pressure}

In another series of experiments depicted in Figure 1, we also found that lice from elephant seals can tolerate hydrostatic pressures equivalent to $2000 \mathrm{~m}$ depth [19], which represents a depth equivalent to seven times the Eiffel Tower under the sea. Moreover, before the experiment, a louse was accidentally exposed to $450 \mathrm{~kg} \mathrm{~cm}-2$ for a couple of minutes, and it survived. This represents $30 \%$ more hydrostatic pressure than the supported by the deepest marine mammal, i.e. the Cuvier's beaked whale [28] for which a maximum diving depth of $3000 \mathrm{~m}$ was reported. These experiments showed that seal lice exhibit an extraordinary tolerance to hydrostatic pressure (i.e., piezotolerance or barotolerance), including rapid dives and climbs to the surface of their hosts [19]. Another important feature is that seal lice can tolerate the hydrostatic pressure by themselves, in the sense that they do not need to be associated with the host to do so. Therefore, we can assume this ability is an intrinsic feature of echinophthiriids [19] and that insects are intrinsically capable of tolerating these conditions.

Furthermore, taking up the idea of Maddrell that postulated that there is a structural limitation of the tracheal system to tolerate the pressure [5], we can assume that only airfilled parts of the body are affected by high pressures. In this sense, it is expected that only the tracheal and the digestive systems collapse during diving. Therefore, we can expect that the louse expels all the air from the tracheal system to tolerate this collapse. If, as we mentioned before, lice survive the long trips at sea maintaining a basal metabolism, the unresolved question is how they can survive without atmospheric oxygen. In this sense, some adaptations present in many other insects could be associated, one is the ability to obtain oxygen from the water (through tegumentary diffusion or a plastron) and another is the storage of oxygen associated to respiratory pigments. Even though infrequent in insects, these pigments have been found in species living in environments where oxygen is scarce or its availability erratic $[29,30]$.

\section{Conclusions and future research}

Beyond any doubt, seal lice are quite unique insects. Their long evolutionary history in association with amphibious hosts, combined with obligatory ectoparasitic nature along with their whole hemimetabolous life, have exposed them to selective pressures that no other insect experiences. The understanding of the specific morphological, physiological, and behavioral adaptations making it possible to tolerate the extreme conditions that they endure during their ectoparasitic life has just begun. A major piece of information recently acquired is particularly revealing: they do not die during the long excursions in the open sea of their deep-diving hosts. As trivial as this assertion could appear, it puts aside the conservative idea that lice would die in the sea and those remaining in the mainland would somehow survive and wait for the return hosts ashore the next reproductive season. Their capacity to survive in extreme environments being adequately confirmed, we can now focus on the next scientific challenge, i.e., explaining how. The previous sections present some hypotheses to be tested and research leads to follow, which should help to complete the puzzle.

Beyond their own biology, seal lice push us to abandon the vision that "insects are not made to survive in the ocean", based on arguments related to their body plan, as their 
respiratory system or non-transparency. Our present knowledge does not reveal unique or extraordinary structural or physiological adaptations in seal lice explaining their extraordinary endurance. On the contrary, simply the adequate combination of characteristics present in many other insects could justify their performances, at least hypothetically.

So, if insects are able to live in the oceans, a legitimate question is why are there virtually absent? The study of seal lice has begun to shed some light on this major question in entomology and we hope that they will continue to do it in the close future, despite the constraints imposed on scientists by their particular biology.
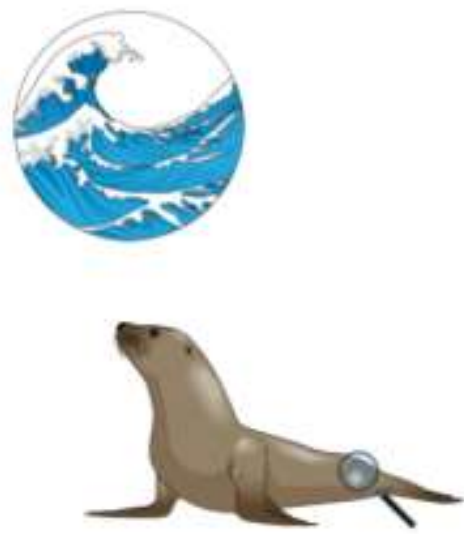
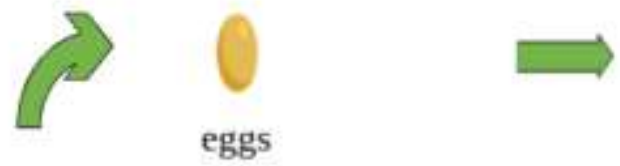

eggs
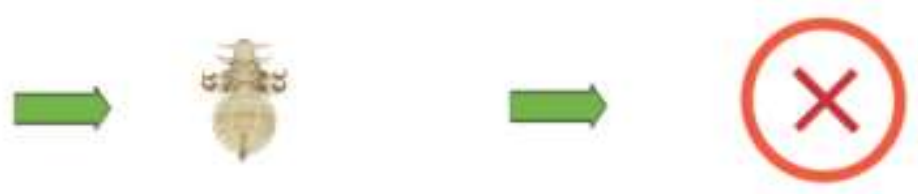

\section{N1}
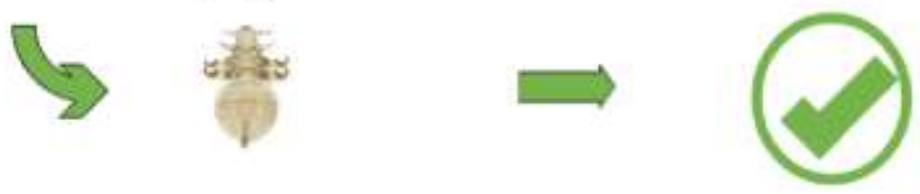

N2/N3+Ad

Figure 1. Differential tolerance to immersion in seawater of seal lice. Only advanced nymphs and adults survive, but not eggs or early nymphs.
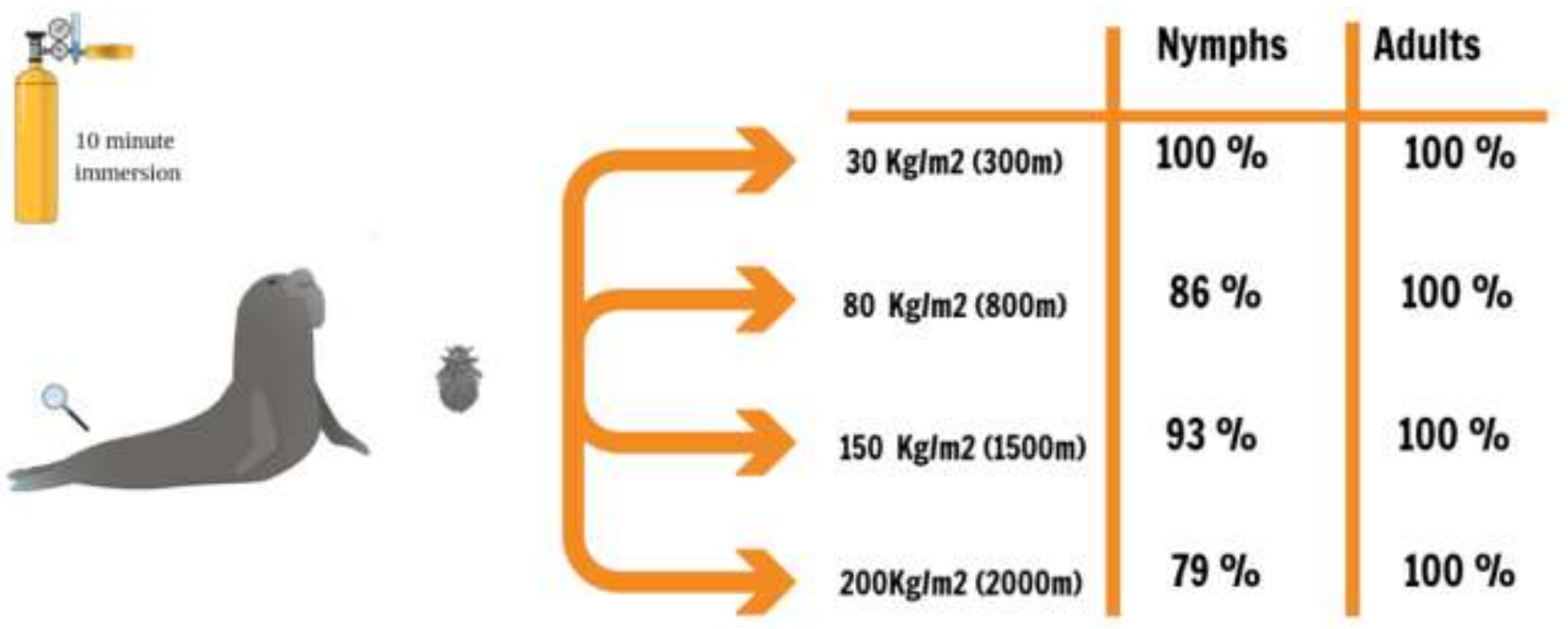

Figure 2. Tolerance to high hydrostatic pressure in seal lice, tested in a hyperbaric chamber, simulating different diving depths. 
Author Contributions: Conceptualization, M.S.L., F.S., J.E.C, and C.L.; investigation, M.S.L., F.S., J.E.C, and C.L.; resources, M.S.L. and C.L.; data curation, M.S.L., J.E.C, and C.L.; writing - original draft preparation, M.S.L and C.L.; writing-review and editing, M.S.L, J.E.C and C.L.; project administration, M.S.L. and C.L.; funding acquisition, M.S.L. and C.L. All authors have read and agreed to the published version of the manuscript.

Funding: This research was funded by PICT 2015-0082 and 2018-0536, Lerner Gray Fund for Marine, and Centre National de la Recherche Scientifique.

Institutional Review Board Statement: The study was conducted according to the guidelines and under the permits of the Secretaría de Áreas Protegidas y Turismo and the Dirección de Fauna y Flora Silvestre, Chubut Province (Argentina).

Informed Consent Statement: Not applicable.

Data Availability Statement: Not applicable.

Acknowledgments: The authors thank Ricardo Vera, Julio Rua, Lorna Eder, Eliana Lorenti, and Sebastián Poljak for their invaluable assistance in the fieldwork. Thanks are also given to the restored Ministerio de Ciencia, Tecnología e Innovación Productiva de la Nación for the promotion of the scientific Argentinean program and the support to public education. We also want to express our heartfelt gratitude and appreciation to all the healthcare workers and researchers working in the frontline against the pandemic for COVID-19.

Conflicts of Interest: The authors declare no conflict of interest.

\section{References}

1. Bradley, T.J.; Briscoe, A.D.; Brady, S.G.; Contretras, H.L., et al. Episodes in insect evolution. Integr Comp Biol 2009, $49,590-606$.

2. Cheng, L. Marine Insects. American Elsevier Publishing Company Inc., New York; 1976.

3. Spence, J.R.; Anderson, N.M. Biology of water striders: interactions between systematics and ecology. Annu Rev Entomol 1994, 39, 101-128.

4. Ruxton, G.D.; Humphries, S. Can ecological and evolutionary arguments solve the riddle of the missing marine insects? Mar Ecol 2008, 29, 72-75.

5. Maddrell, S.H.P. Why are there no insects in the open sea? J Exp Biol 1998, 201, 2461-2464.

6. Kim, K.C. Coevolution of parasitic arthropods and mammals; Wiley, New York; 1985.

7. Bush, A.O.; Fernández, J.C.; Esch, G.W.; Seed, J.R. Parasitism: The Diversity and Ecology of Animal Parasites. Cambridge University Press, UK; 2001.

8. Durden, L.A.; Musser, G.G. The sucking lice (Insecta, Anoplura) of the world: a taxonomic checklist with records of mammalian hosts and geographical distributions. Bull Am Mus Nat Hist 1994, 218, 1-90.

9. Leonardi, M.S.; Palma, R.L. Review of the systematics, biology and ecology of lice from pinnipeds and river otters (Insecta: Phthiraptera: Anoplura: Echinophthiriidae). Zootaxa 2013, 3630, 445-466.

10. Stewart, B. Diving behavior. In Encyclopedia of Marine Mammals; Perrin, W.F., Würsig, B., Thewissen, J.G.M., Eds.; San Diego: Academic Press, 2009; pp. 321-327.

11. McIntyre, T.; de Bruyn, P.J.N.; Ansorge, I.J.; Bester, M.N.; Bornemann, H.; Plötz, J.; Tosh, C.A. A lifetime at depth: vertical distribution of Southern elephant seals in the water column. Polar Biol 2010, 33, 1037-1048.

12. Teilmann, J.; Born, E.W.; Aquarone, M. Behaviour of ringed seals tagged with satellite transmitters in the North Water polynya. Can J Zool 1999, 77, 1934-1946.

13. Leonardi, M.S., Virrueta Herrera, S., Sweet, A., Negrete, J. Johnson, K.P. Phylogenomic analysis of seal lice reveals codivergence with their hosts. Syst Entomol 2019, 44, 699-708.

14. Murray, M.D.; Smith, M.S.R.; Soucek, Z. Studies on the ectoparasites of seals and penguins. II. The ecology of the louse Antarctophthirus ogmorhini Enderlein on the Weddell seal, Leptonychotes weddelli Lesson. Aust J Zool 1965, 13, 761-771.

15. Leonardi, M.S.; Lazzari, C.R. Uncovering deep mysteries: the underwater life of an amphibious louse. J Insect Physiol 2014, 71, 164-169.

16. Aznar, F.J.; Leonardi, M.S.; Berón-Vera, B.; Vales, D.G.; Ameghino, S.; Raga, J.A.; Crespo, E.A. Population dynamics of Antarctophthirus microchir (Anoplura: Echinophthiriidae) in pups from South American sea lion, Otaria flavescens, in Northern Patagonia. Parasitology 2009, 136, 293-303.

17. Soto, F.A.; Klaich, M.J.; Negrete, J.; Leonardi, M.S. So happy together: juvenile crabeater seal behavior improves lice transmission. Parasitol Res 2020, 119, 2059-2065.

18. Leonardi, M.S.; Crespo, E.A.; Raga, J.A.; Aznar, F.J. Lousy mums: patterns of vertical transmission of an amphibious louse. Parasitol Res 2013, 112, 3315-3323.

19. Leonardi, M.S.; Crespo, J.E.; Soto, F.A.; Vera, R.B.; Rua, J.C.; Lazzari, C.R. Under pressure: the extraordinary survival of seal lice in the deep sea. J Exp Biol 2020, 223 (17). 
20. Murray, M.D. Insect parasite of marine bird and mammals. In Marine Insects; Cheng, L., Ed.; American Elsevier Publishing Company Inc., New York; 1976, pp. 78-96.

21. Murray, M.D.; Nicholls, D.G. Studies on the ectoparasites of seals and penguins I. The ecology of the louse Lepidophthirus macrorhini Enderlein on the Southern Elephant seal, Mirounga leonina. Aust J Zool 1965, 13, 437-454.

22. Kim, K.C. Ecology and morphological adaptation of the sucking lice (Anoplura, Echinophthiriidae) on the Northern Fur seal. Rapp p-v Reun Cons Int Explor Mer 1975, 169, 504-515.

23. Leonardi, M.S.; Crespo, E.A.; Raga, J.A.; Fernández, M. Scanning electron microscopy of Antarctophthirus microchir (Phthiraptera: Anoplura: Echinophthiriidae): Studying morphological adaptations to aquatic life. Micron 2012, 43, 929-936.

24. Leonardi, M.S.; Crespo, E.A.; Raga, J.A.; Fernández, M. Redescription of Antarctophthirus microchir (Anoplura: Echinophthiriidae) from the South American sea lion, Otaria flavescens, from Patagonia, Argentina. J Parasitol 2009, 95, 10861092.

25. Kim, K.C. The sucking lice (Anoplura: Echinophthiriidae) of the northern fur seal; descriptions and morphological adaptation. Ann Entomol Soc Am 1971, 64, 280-292.

26. Mehlhorn, B.; Mehlhorn, H.; Plötz, J. Light and scanning electron microscopical study on Antarctophthirus ogmorhini lice from the Antarctic seal Leptonychotes weddellii. Parasitol Res 2002, 88, 651-660.

27. Hinton, H.E. Respiratory adaptations of marine insects. In Marine Insects; Cheng, L., Ed.; American Elsevier Publishing Company Inc., New York; 1976, pp., pp. 43-78.

28. Schorr, G.S.; Falcone, E.A.; Moretti, D.J.; Andrews, R.D. First longterm behavioral records from Cuvier's beaked whales (Ziphius cavirostris) reveal record-breaking dives. PLoS ONE 2014, 9, e92633.

29. Chapman, R.F. The insects: structure and function. Cambridge university press, UK, 1998.

30. Hagner-Holler, S.; Schoen, A.; Erker, W.; Marden, J.H.; Rupprecht, R.; Decker, H.; Burmester, T. A respiratory hemocyanin from an insect. PNAS 2004, 101, 871-874. 